\title{
Is the Study Abroad (SA) Program Important for Indonesian Students?
}

\author{
Dodi Widia Nanda ${ }^{1}$ \\ ${ }^{1}$ Faculty of Education, University of Dharmas Indonesia (UNDHARI), Indonesia \\ Correspondence: Dodi Widia Nanda, Faculty of Education, University of Dharmas Indonesia, West Sumatera, \\ Indonesia.
}

Received: June 1, 2019 Accepted: July 10, 2019 Online Published: July 12, 2019

doi: 10.5539/elt.v12n8p69 URL: https://doi.org/10.5539/elt.v12n8p69

\begin{abstract}
This paper aims to investigate how the concept of language, culture, identity and difference work together in the implementation of the SA Program for Indonesian students and how important its application for them. Concerning the interrelatedness between the four concepts in the employment of SA program, it is found that there is a chance for Indonesian learners to create new cultures after having interaction and dialogues through English as the target language. They also construct their new identity as people who have high-skills in English, in which they are marked out differently by other people. Furthermore, regarding the importance of joining in the SA program, it is seen that the program is vital to improve students' language skills, affect their cultural transformation and increase their level of confidence in using English. However, it should be applied carefully and put some considerations due to some challenges, including the limitation of English competence, the different of learning culture characteristics, the likelihood of crisis identity. Hence, all of the emerged insights above might be beneficial for policymakers of the SA program to revisit the regulation and enhance the quality of their guided SA program. Then, it may be useful as well for the SA program educators to design and employ suitable learning strategies to be suitable with students' demands. Ultimately, it can be useful insights as well for students to be well-prepared before joining the SA program.
\end{abstract}

Keywords: culture, difference, identity, language, study abroad program

\section{Introduction}

\subsection{Background}

The existence of studying abroad (SA) program has been considered a topical issue in an educational field. Some people believe that SA program might be essential to enhance students' language development, increase their multicultural understanding and broaden their future lives such as applying for jobs and enrolling to tertiary education (Emanoil, 1999; Mpinganjira, 2009; Norris \& Gillespie, 2009). Moreover, the SA program, regardless of its length and destination, has had a significant impact on all of the foreign language subskills such as reading, writing, listening and speaking (Kinginger, 2011). While, some others reveal that SA program will not provide positive outcomes for learners because it is not suitable for learners' needs and financial support (Meid, 2003). In line with the opinion above, Cubillos, Chieffo, and Fan (2008) assert that SA program will not always guarantee the students' linguistic gain and deep cultural understanding because the designed activities are not appropriate with students' needs.

This hotly debated issue has been identified as well in the Indonesian context. Based on my cousin's and students' experiences, the implementation of studying abroad had shown different results. To exemplify, my cousin-brother who studied Math in a higher education deciding to join a SA program held in the USA for about three months. After finishing the related program, his English proficiency had experienced a remarkable improvement, which made him elected as an English news-anchor in one of the Indonesian broadcastings. On the other hand, some of my students who took the SA program in English-speaking countries obtained different outcomes after getting back from the given program. It seemed that there was no considerable improvement made by them regarding their English skills, such as productive and receptive skills.

\subsection{The Context of the SA Program}

In an attempt to contextualise the issue and discussion, this paper will only discuss the SA program which is specially designed and given for Indonesia students who study English for a short-term duration in English speaking countries such as Australia, USA, UK and Canada. The SA program that can be defined as educational 
programs which take place outside the geographical boundaries of the home country (Kitsantas, 2004), occurring at least 3-4 weeks, and maximally one semester of the length of student sojourn (L. Engle \& J. Engle, 2004). Hence, it is not a studying abroad that is taken by Indonesian students at a formal setting such as taking a secondary level in overseas or pursuing undergraduate and post-graduate degrees in English speaking countries.

In addition, concerning the level of students, the writer will not limit between the secondary and university students because the culture of valuing SA program has been produced and consumed by both levels to enhance their English language skills. Moreover, Hall (1997) reveals that the produced and consumed meaning affect the humans' ways of thinking and behaving. Hence, that is the reason why Indonesian students at both levels have been spending their time and money for studying overseas to increase their language competence.

\subsection{English Language Teaching and Learning in Indonesia}

Since 1945, In the year of Indonesian independence, English language teaching and learning has been integrated and taught in secondary schools, and with the increasing of Indonesian government's awareness of the significant role of English, it has been taught as well in a tertiary education and even primary schools (Cahyono \& Widiati, 2004; Lie, 2007; Mattarima \& Hamdan, 2011; Nababan, 1991). Moreover, in the new curriculum, the curriculum in Indonesia under the regulation of The Ministry of Education and Culture Number 65/2013 mandates the English teachers to implement a classroom activity which is specifically designed to trigger learners to participate actively in learning activities (Ministry of Education and Culture, 2013). Moreover, students have been encouraged to participate in classes which consist of international students and lecturers, and they have been required to introduce Indonesian culture in International arenas (Cahyono \& Widiati, 2004; Lamb \& Coleman, 2008).

Therefore, based on the required condition above, many Indonesian students have had a high obsession with studying overseas where English used and taught as a first language in order to boost their English competence which allows them introducing Indonesian culture in the target country. However, the problems happen when Indonesian people have had a different view regarding the effective ways to increase English skills. Some Indonesian contend that it is a sensible idea for Indonesian students studying in faraway places to improve their language skills and western culture because studying abroad is essential to improve cross-cultural skills and global understanding (Kitsantas, 2004). On the other hand, some others postulate that it is not necessary for Indonesian learners to study English in western countries because the local context should be mainly prioritised in English language teaching. Moreover, Kirkpatrick (2001, as cited in Cahyono \& Widiati, 2004) asserts that local context itself has to be a central part of English curriculum because learners should be exposed to a culture that familiar to them which results in a better understanding of their English. However, the adoption of local culture itself has been categorised a central issue in Indonesian ELT. The given approach to implement a local culture in ELT has not been successful because the instructions and content still imitate the practice of western countries (Cahyono \& Widiati, 2004). Consequently, the implementation of ELT in Indonesia has not been adequate to strengthen learners' English competences. Therefore, the condition and issue above might be the leading factor of topical debate regarding the importance of SA program for Indonesian students. The detailed discussion of the SA program will be explained more in the discussion part below:

\subsection{Significance}

Based on the issue and different experiences above, the writer would like to investigate more what is actually happening in the SA program. How the concept language, culture, identity and difference work together in the implementation of the SA program? Is it essential for Indonesian students? Furthermore, the result of this paper is hoped to be valuable sources for individuals and institutions that have been involving in the SA program. It can be used by policymakers like faculty directors and administrators of the SA program to revisit the regulation and enhance the quality of their guided SA program. Then, it can be utilised by the SA program educators or tutors to design and implement suitable learning activities and methods to fit in with students' demands, and it can be useful sources as well for students to be well-prepared before joining the SA program.

Thus, in order to contextualise the issue and discussion, the writer will describe the context of the SA program and the level of students discussed in this essay. Then, it will be followed by the explanation of English language teaching and learning in Indonesia. Next, the writer will discuss the theoretical background comprises the relatedness between the topic and the concept of language, culture, identity and difference. It is followed by the discussion of the positive sides, the challenges, and considerations of the SA program which link with the concept of language, culture, identity and difference. Ultimately, the paper will be concluded by giving a summary and suggestions regarding the implementation of the SA program. 


\subsection{Research Questions}

1). How the concept of language, culture, identity and difference work together in the application of the SA program for Indonesian students?

2). How is the importance of the SA program for Indonesian students?

\section{Method}

This paper scrutinised existed literature reviews, in which some academic works relevant to the topic were critically selected. The literature was gathered from a plethora of resources, including articles from reputable academic journals, books and others. Then, the selected literature was analysed and evaluated critically to find the information needed. Lastly, the suitable information and evidence were used to foster sound arguments in the paper. Hence, the detailed discussion is elaborated below:

\section{Results and Discussions}

\subsection{Theoretical Background: Relating the Topic to the Concept of Language, Culture, Identity and Difference}

In an attempt to give an interconnection between the topic and the concept of language, culture, identity and difference, the writer specifically synthesises the specific aspects of Vygotskian and Bakhtinian theories, the two Soviet visionaries. Both Vygotsky and Bakhtin have a similar view, stating that language is always immersed in a social context, and it is used to facilitate communication (Jackson, 2008). Based on the definition of language above, it can be inferred that language use and development could be trained maximally through interaction with other people. In my view, it is applicable with the SA program settings in which learners are required to interact and communicate with their peers, tutors and even native speakers in the given program which might be beneficial to strengthen their language competence.

Moreover, both Vygotsky and Bakhtin also agree that human interaction through language plays a pivotal role in the forming of culture. Bakhtin defines culture as the product of human interaction (Jackson, 2008), and social activities of a human being (Vygotsky, 1987, as cited in Jackson, 2008). Therefore, by joining in the SA program, there is a likelihood of having a new culture which is affected by the students' interaction and activities in the designed program. To exemplify, a culture of using term 'mate' after joining a SA program held in Australia. As we know that Australian particularly youngsters tend to use the related term to show intimacy with other people, and it is used as a form of address (Rendle-Short, 2009). If students who originally come from an Eastern culture such as Indonesian are joining in SA program implemented in Australia, it might affect them using the term 'mate' which is uncommon for them before. The related condition occurs because they are influenced by the Australian tutors and even Australian societies who use the related term in interacting with them in the SA program.

Furthermore, concerning the identity which occurs in the SA program, both Vygotsky and Bakhtin also have had the same understanding, postulating that language reflected by dialogue is beneficial for the development of humans' identity. Moreover, Bakhtin (1986, as cited in Jackson, 2008) postulates that dialogue with other people throughout our lives is essential to routinely shape and reshape our sense of self-identity. That is the reason why in the SA program, learners who communicate in the target language, particularly in the oral forms, could shape their new identity (Benson, Barkhuizen, Bodycott, \& Brown, 2013). For instance, after having interaction or dialogues with a native speaker of the target language, English. Indonesian learners who join in the SA program will imitate a particular English expression like "get the ball rolling' which means "to start something. The meaning of related expression might be challenging to understand by people who never study overseas for learning English or those who only learn English in formal settings (classroom) because such expression might be easily found in a daily conversation done with native speakers. Hence, learners who joined in SA program could be identified as people who have high-competence in English compared to those who do not, because they have striven to learn the English language in faraway places and have known certain English expressions which are uncommon for those who learn English minimally. Based on the situation above, identity could be defined and theorised as diverse, site to struggle (Peirce, 1995), and it will never remain static (Woodward, 1997).

Ultimately, identity itself is marked out by difference, in which the difference will signify the specific identities from other identities and create distinctions. The marking of the difference happens through the symbolic system of representation called the classificatory system, in which it is categorised as a functional system used to apply a principle of difference to populations and divide their characteristics into at least two opposing groups (Woodward, 1997). The related marking of difference might also occur as an effect of SA program of learning English, Indonesian students who have accomplished the given program will be marked out as capable English learners, and they will be looked up by Indonesian societies. On the other hand, Indonesian learners who do not 
join in the SA program will be regarded as low-competent students. Hence, it can be inferred that the marking of difference affected as well by the existence of the SA program.

\subsection{The Positive Sides of Joining in the SA Program which Link with Language, Culture, Identity and Difference}

\subsubsection{Language Development}

The first positive point of joining in the SA program would be learners' language development. The related language development will be obtained by involving in group activities guided by more capable others such as peers and tutors. This phenomenon and opinion supported by a notion proposed by Vygotsky (1978, as cited in Woolfolk \& Margetts, 2016), called the Zone of Proximal Development (ZPD). In this view, the development of language will be easily obtained by students if they are involved in group activities guided by More Knowledgeable Other (MKO) (Candlin \& Hall, 2012). Regarding the implementation of SA program, based on my cousin-brother's experience who have taken SA program in the USA, he had been given the related group activities which are guided by their tutors to increase their language competence. For instance, the implementation of let's chat program, my cousin-brother and his friends were required to have a chat each other to discuss any topics given by their tutors in the related program, and the discussion guided and watched by the tutors, indeed. Then, they will deliver their ideas toward the given topic by using the target language; any mistakes in the language use made by them could be easily corrected by their tutors. Hence, it might automatically increase their language development as well as their confidence in using the target language.

Moreover, Halliday (1973, as cited in Candlin \& Hall, 2012) postulates that language could be categorised a sociocultural resource established in the social lives. In other words, language development could be obtained by people when they actively engage with social lives. This view is relatable with the advantage offered by joining in the SA program, in which students will be given many chances to interact and involve in social circumstances. This condition is supported by the valuable chances experienced by Cindy, a Hong Kong student who took the SA program in the USA (Benson et al., 2013). Based on Cindy's experiences, she had obtained considerable opportunities to join and socialise with social communities, whether with the host family in the country or his assigned buddy (Benson et al., 2013). As a consequence, it had given a significant impact on her English development since she practices her English intensively when doing socialisation and interaction with her surroundings.

\subsubsection{The Students' Culture in Communicating and Interacting With Others}

Another positive impact of joining in the SA program might be students' transformation concerning their communication style in interacting with other people. The humans' style is categorised as a culture as well, and culture is fundamentally heterogeneous and changing over time (Kramsch, 1998). By studying abroad, Indonesian learners' culture regarding their style in interacting with others might experience some changes as well. To exemplify, before study abroad experiences, Asian people such as Indonesian people tend to downplay any compliments given by other people (Kramsch, 1998); if they were praised: 'I like your T-shirt!' - their response would be 'Oh really? It is already quite old, anyway!' Based on the illustration above, it can be inferred that Indonesian people are likely to minimise the value of compliment; however, it could be transformed when they are studying overseas in Western countries like in America. The American culture has been socialised into responding 'Thank you' to any given praise (Kramsch, 1998). Hence, there might be possibilities that Indonesian students will be affected by the related culture to say "thank you" directly after they are given any compliments by others.

Moreover, the learners' transformation above is categorised a synchronic (social) layer of culture. In this notion, people will acquire the same ways of viewing the world when they belong to the same group (Kramsch, 1998). It occurs because when they join in the same group, they will socialise and share any ideas, which results in their mutual understanding into many things. So that is the reason why Indonesian learners who previously used to downplay given compliments might automatically change the related way after socialising with people in the new environment or countries such as America.

\subsubsection{The Transformation of Students' Identity: Self-confidence}

Joining in the SA program might result in the transformation of humans' identity, such as self-confidence. In the context of language learning, self-confidence could be defined as self-perceptions of humans' abilities in using the target language (Noels, Pon, \& Clement, 1996), and self-confidence is part of humans' identity and it always changes dramatically over time which depends on peoples' interaction and engagement with the target language speakers (Peirce, 1995). In other words, the increased self-confidence in language learning will be obtained through the frequency and quality of contact done with target language groups. This view is relatable in the 
context of SA program in which learners will be given such well-organised activities in the related program as well as sufficient time to interact with the target language speaker like the chosen tutor (Amuzie \& Winke, 2009). By involving in the SA program, the learners will be required to challenge themselves using the target language as much as possible to absorb and follow the learning materials given by their tutors.

On the other hand, the opportunities above might be laboriously obtained by Indonesian students in their home country since they have not been given enough chances to use English language in the classroom as well as outside the classroom (Erlenawati, 2002). So that is why by involving in the SA program, Indonesian learners will foster their new identity as people who use English confidently since they are given valuable and significant time to interact with the target language speakers to boost their English language competence. Therefore, Gardner (1985) accentuates that self-confidence is affected by a positive experience in language learning, and it is beneficial to motivate students to learn.

Based on the three explained positive sides above, it can be inferred that the SA program has had a valuable contribution on students' language development, the transformation of culture regarding the learning style in interacting with other people and the establishment of students' identity regarding the enhanced self-confidence. However, joining in the SA program may be challenging as well for Indonesian students, and the detailed discussion of the related challenges will be discussed below:

\subsection{The Challenges of Joining in the SA Program which Link with Language, Culture, Identity and Difference}

\subsubsection{Language Difficulties}

The first challenge of joining in the SA program for Indonesian learners would be language difficulties. Hall (2013) reveals that language is not only essential to construct meaning, but also it is beneficial to facilitate our communication with other people to understand each other. That is the reason why those who intend to join in the SA program should be selected carefully before going overseas, in which the selected participant at least should be categorised as a modest user of English. Otherwise, there will be some issues that might occur in the implementation of the SA program, such as the misunderstanding between the participants and tutors in interpreting the given instructions, activities, and so on. However, although the chosen students have had enough skills in the English language before studying overseas but having the first time studying overseas in English-speaking countries for Indonesian students is not an easy task since they are required to speak and communicate in the English language every day. Whereas in fact, the required condition might be problematic for Indonesian learners because they do not get used to using English in their daily activities (Erlenawati, 2002).

Moreover, a study conducted by Nguyen (2011) shows that Indonesian students have had difficulties in pronouncing English words, particularly consonant classes and word-ending like 'sh', 's', 't', 'd', 'g', ' $x$ ' and 'j'. This particular issue might be problematic as well for Indonesian students in communicating and interacting with the native speakers in SA program because if they cannot pronounce English words correctly, they will not hear the English speakers properly since listening and speaking go together (Nguyen, 2011). Consequently, this limited English language proficiency could cause Indonesian students to be perceived by the target language speakers or their peers as intellectually inferior in the SA program, which may give way to frustration and lowered self-esteem.

\subsubsection{The Cultural Difference in Learning}

Another issue in the implementation of the SA program for Indonesian learners would be the cultural disparities in learning, particularly the discrepancies of learning style. The language learning style could be categorised one of the representations of culture (Nguyen, 2011), and it is beneficial to support the successful path of studying abroad. In other words, the more similar students' learning styles with the target language learning style, the more opportunities to be successful learners in involving in the SA program. However, in the context of Indonesian learning style and Western learning style, there has been plenty of discrepancies between the two learning styles, which may hinder Indonesian learners' development in studying in English-speaking countries. For instance, Asian students like Indonesian learners have been categorised passive learners and lack of critical thinking (Nguyen, 2011), while in Western culture, students have been asked to be active learners (Nguyen, 2011). Hence, there are significant disparities in learning styles between the Indonesian learners' styles and Western culture, which may give way to an ineffective learning process.

Moreover, to be specific, a study conducted by Novera (2004) finds that there have been significant issues regarding cultural differences in a learning style that Indonesian students have to face in taking the SA program in English speaking countries, which are power distance. Power distance could be defined as how people belong to a particular culture view power relationship unequally. It could be barriers for Indonesian learners in adjusting 
to a new environment because Indonesian highly values the power distance (Novera, 2004). For instance, Indonesian get used to obey and respect older people or more educated people like lecturers by using particular language codes such as 'Sir', 'Mr', and 'Ms', while in Western culture lecturers are often addressed by their first names only (Novera, 2004). Moreover, to show their respect for older people such as teachers and lecturers, Indonesian students prefer to show indirect signals than to argue directly with their teachers or lecturers because interrupting and asking questions to lecturers in the middle of presentation considered an impoliteness and rudeness (Novera, 2004). Hence, the related behaviour above would be culturally appropriate in Indonesia, but it can be categorised a classroom passivity in Western culture.

\subsubsection{The Emergence of Crisis of Identity}

The emergence of the crisis of identity would be another challenge that Indonesian learners have to face in joining the SA program. The crisis of identity could be defined as a period of confusion and uncertainty, in which the old identities assumed to be fixed, stable and coherent displaced by the experience of doubt and uncertainty (Hall, Held, \& McGrew, 1992). Moreover, Woodward (1997) reveals that a crisis of identity is affected by globalisation, in which it is characteristic of modernity in the context of the global transformation. On the other hand, the SA program itself is a part of globalisation (Loew, 1980), in which the students are taught from a global perspective. In other words, learners are required to comprehend this world as a dynamic global system, and they are asked to collaborate and engaged with heterogonous societies and new culture in the SA program. Consequently, the learners will face a new culture which might be possibly threat local culture or identity and may replace into the new identity. Hence, it could be mentioned as a crisis of identity since there is an encounter between learners' old identity and the incoming identity which may lead to confusion and uncertainty (Hall et al., 1992). Therefore, to anticipate the challenges above, there are some considerations that Indonesian students must learn and do in involving in the SA program. The related considerations will be discussed below:

\subsection{The Considerations}

\subsubsection{Being Active Learners}

Being an active learner would be a sensible idea that Indonesian students should do in involving in the SA program. It means they must actively find out a supportive learning environment such as putting themselves to be surrounded by target language speakers. In line with the related opinion, Tsui and Tollefson (2017) assert that finding and having a positive learning environment is a must for language learners to be welcomed as international students to enhance their language competence. For instance, registering as volunteers in unpaid community services in the host countries, joining in sport and student social group communities and others. By doing this way, they will be given such significant opportunities to share and practice the target language intensively which is beneficial to boost their language acquisition as well as their level of confidence in using the target language.

\subsubsection{Students Must Learn about the Culture of the Host Countries before Joining in the SA Program}

Learning and understanding more about the culture of the host countries before starting the SA program would be a positive idea as well for Indonesian learners who decide to study abroad. In line with the related opinion, Kitsantas (2004) suggests that International students must be urged to analyse more about the culture and people in the places in which they will study. It is needed to cope with some crucial issues such as the different learning styles which may give way to an ineffective learning process. In other words, comprehending the target countries' culture like its learning styles before the departure would assist learners to comprehend and asses some required passions and skills to adapt smoothly to the learning environment. For example, Indonesian learners could learn and train themselves to be active learners who are not reluctant to express any ideas in front of the class since the related learning style is needed to engage with learning process given in the western cultures. Whereas in fact, Asian students such as Indonesian students are still categorised passive learners who are not confident enough to do so (Nguyen, 2011).

\subsubsection{Students Must Be More Cross-culturally Sensitive}

Having more cross-cultural sensitivity would be a wise idea for those who intend to study abroad. Cross-cultural sensitivity defined as the level of people' awareness about the existence of cultural similarities and differences around the globe and those who have high-awareness of the cross-cultural sensitivity will have better understanding and knowledge regarding intercultural competence (Fritz, Mollenberg, \& Chen, 2001). In other words, people who have related ability will be sensitive enough to comprehend cultural similarities and differences, and they will behave appropriately to respect other cultures. In my view, this specialised skill is beneficial for Indonesian students who take SA program because it will support their critical thinking skills to 
filter any incoming information and knowledge obtained in the target culture. As a consequence, it may hinder their crisis of identity while studying abroad because they will have enough abilities to anticipate the encounter between their old identity and the new one.

\section{Conclusions}

\subsection{Brief Summary}

In summary, to answer the first research question related to how the concept of language, culture, identity and difference work together in the implementation of the SA program. The paper will summarise the main features of the interrelatedness among the four concepts in the implementation of the SA program that has been already discussed in the discussion part (theoretical background) of the paper. To put it simply, culture has been categorised an outcome of social processes affected and shaped by human interaction, particularly dialogue. Then, the human interaction and dialogue itself facilitated by language, which has a function to construct humans' identity, and the related identity itself is marked out by the difference. Based on the interconnection among the four concepts above, it can be linked with the principle of SA program, in which by joining in the related program, there will be an opportunity for learners to create new cultures after having interaction and dialogues with their peers or tutors in the host country. For instance, a culture of using particular English words or expressions that are challenging to be understood by those who have not studied abroad or an English course, in which they will construct their new identity as people who have high-skills in English. Moreover, they will be marked out different and looked up by Indonesian societies, whereas those who have not studied abroad will be looked down and marked as low-competence students by others. Thus, the marking of difference has already existed as well in the SA program.

Furthermore, in an attempt to answer the second research question regarding the importance of joining in the SA program for Indonesian students, the writer argues that studying abroad is vital to improve learners' language skills, positively affect students' cultural transformation regarding their interacting style, and increase the students' level of confidence in using the target language, English. However, it should be implemented carefully and put under some considerations as well due to some challenges (Buckingham, 1989; Burns, 1991; Samuelowicz, 1987). The limitation of prior English language competence faced by the majority of Indonesian students to communicate effectively with native speakers, the different background culture between Indonesian culture and Western culture regarding the students' learning characteristics which may give way to ineffective learning, and the likelihood of crisis of identity arises after Indonesian students taking the SA program due to the encounter between the old identity and the new identity obtained in the SA program. However, the challenges above can be minimised by instructing and encouraging the Indonesian students to be active learners while studying abroad like finding positive learning environments to train and improve their English language skills, being motivated to learn the target culture to cope with the learning characteristic disparities and being more cross-culturally sensitive as a buffer against uncertainty which may lead to crisis of identity. Based on the topical debate between the importance and challenges of the SA program above, it can be inferred that this issue could be categorised a complex issue in an educational field.

As a reflection, although some studies have found that the implementation of SA program as an excellent way to improve students' development, particularly their language acquisition and multicultural understanding (Benson et al., 2013; Gray, Murdock, \& Stebbins, 2002; Vidal, 2014). However, the writer believes that there have been some weak points that the related program has, which may hinder the rapid evolution of students' abilities in mastering the target language and having multicultural understanding. This opinion appears when there have been certain cases where learners do not obtain remarkable improvement after joining in the related program. For instance, my students' experiences discussed in the introduction part of the paper, in which they did not have significant improvement in their English language acquisition after getting back from the SA program. Therefore, the detailed suggestion to improve the implementation of the SA program is offered below:

\subsection{Suggestions}

In order to enhance the quality of SA program given to students, study abroad faculty directors, administrators, tutors and even the students have to make some concerted efforts; firstly, formal instructions can be given to the students. For instance, the implementation of SA program should be started by assessing the coursework in order to measure students' pre-abilities before joining in the given learning activities which are used to evaluate their improvements in the on-going process. Secondly, the homestay setting in the host country might be given to students to provide them with better opportunities to keep in touch and interact with the native speakers of the target language and culture which is beneficial to enhance their language skills and self-confidence. Thirdly, providing peer-mentor program would be a sensible idea to help students in adapting with the given learning 
atmosphere and assist them to cope with students' distress, which may be affected by their first experience living abroad. Ultimately, the students should prepare themselves physically and mentally to deal with the new environment and cultural shock. Based on some suggestions above, it can be seen that the implementation of the SA program should be considered and implemented carefully to maximise its given benefits. Moreover, Engle and Engle (2004) and Hulstrand (2006) assert that the SA program must be undermined by some elements to maximise its potentialities; length of student sojourn, required language use, the entry target language competence, the given coursework, the given mentoring or guided cultural reflection, the experiential learning initiatives and the homestay setting.

\section{Acknowledgements}

I would like to acknowledge The Indonesian Endowment Fund for Education (LPDP) for the grant given to the author in this paper.

\section{References}

Amuzie, G. L., \& Winke, P. (2009). Changes in language learning beliefs as a result of study abroad. System: An International Journal of Educational Technology and Applied Linguistics, 37(3), 366-379. https://doi.org/10.1016/j.system.2009.02.011

Benson, P., Barkhuizen, G., Bodycott, P., \& Brown, J. (2013). Second language identity in narratives of study abroad. London, UK: Palgrave Macmillan. https://doi.org/10.1057/9781137029423

Buckingham, D. A. (1989). The role of government. In R. K. Browne, \& E. C. Dale (Eds.), Overseas Students: Educational Opportunity and Challenge (pp. 60-64). Australia: The Australian College of Education.

Burns, R. B. (1991). Study and stress among first year overseas students in an Australian university. Higher Education Research and Development, 10(1), 61-77. https://doi.org/10.1080/0729436910100106

Cahyono, B. Y., \& Widiati, U. (2004). The tapestry of English language teaching and learning in Indonesia. Malang: State University of Malang Press.

Candlin, C. N., \& Hall, D. R. (2012). Language and culture learning. In J. K. Hall (Ed.), Teaching and Researching Language and Culture (pp. 47-67). Oxon: Routledge.

Cubillos, J. H., Chieffo, L., \& Fan, C. (2008). The impact of short-term study abroad programs on L2 listening comprehension skills. Foreign Language Annals, 41(1), 157-186. https://doi.org/10.1111/j.1944-9720.2008. tb03284.x

Emanoil, P. (1999). Study abroad expands cultural view, life skills, and academic experience. Human Ecology Forum, 27(3), 10-14.

Engle, L., \& Engle, J. (2004). Assessing language acquisition and intercultural sensitivity development in relation to study abroad program design. Frontiers: The Interdisciplinary Journal of Study Abroad, 10(1), 219-236.

Erlenawati. (2002). Beliefs about language learning: Indonesian learners' perspectives, and some implications for classroom practices. Australian Journal of Education, 46(3), 323-337. https://doi.org/10.1177/00049441 0204600306

Fritz, W., Mollenberg, A., \& Chen, G. M. (2001, July). Measuring intercultural sensitivity in different cultural context. Paper presented at the International Association for Intercultural Communication Studies, Hong Kong. Abstract retrieved from https://eric.ed.gov/?id=ED456491

Gardner, R. C. (1985). Social psychology and second language learning: The role of attitudes and motivation. London, UK: Edward Arnold.

Gray, K. S., Murdock, G. K., \& Stebbins, C. D. (2002). Assessing study abroad's effect on an international mission. Change: The Magazine of Higher Learning, 34(3), 44-51. https://doi.org/10.1080/00091380209 601855

Hall, S., Held, D., \& McGrew, A. G. (1992). Modernity and its futures. Cambridge, UK: Polity Press in Association with the Open University.

Hall, S. (1997). Representation: Cultural representations and signifying practices. London, UK: Sage Publications.

Hall, S. (2013). The work of representation. In S. Hall (Ed.), Representation: Cultural Representations and Signifying Practices (pp. 13-64). London, UK: Sage Publications. 
Hulstrand, J. (2006). Education abroad on the fast track. International Educator, 15(3), 46-55.

Jackson, J. (2008). Language, identity and study abroad: Sociocultural perspectives. London, UK: Equinox Publishing Ltd.

Kinginger, C. (2011). Enhancing language learning in study abroad. Annual Review of Applied Linguistic, 31, 58-73. https://doi.org/10.1017/S0267190511000031

Kitsantas, A. (2004). Studying abroad: The role of college students' goals on the development of cross-cultural skills and global understanding. College Student Journal, 38(3), 441-452.

Kramsch, C. (1998). Language and culture. Oxford: Oxford University Press.

Lamb, M., \& Coleman, H. (2008). Literacy in English and the transformation of self and society in post-Soeharto Indonesia. International Journal of Bilingual Education and Bilingualism, 11(2), 189-205. https://doi.org/10. 2167/beb493.0

Lie, A. (2007). Education policy and EFL curriculum in Indonesia: Between the commitment to competence and the quest for higher test scores. TEFLIN Journal, 18(1), 1-14.

Loew, H. Z. (1980). Language in education: Theory and practice. Washington DC, USA: Center for Applied Linguistics.

Mattarima, K., \& Hamdan, A. R. (2011). The teaching constraints of English as a foreign language in Indonesia: The context of school-based curriculum. Sosiohumanika, 4(2), 287-300.

Meid, J. S. (2003). Asian Americans: Factors influencing the decision to study abroad. Frontiers: The Interdisciplinary Journal of Study Abroad, 9(4), 71-110.

Ministry of Education and Culture (2013). Peraturan Menteri Pendidikan dan Kebudayaan Republik Indonesia Nomor 65/2013 tentang Standar Proses Pendidikan Dasar dan Menengah. [The Regulation of the Minister of Education and Culture of Republic Indonesia Number 65/2013 concerning the Process Standard of Education in Elementary and High School]. Jakarta: Author.

Mpinganjira, M. (2009). Comparative analysis of factors influencing the decision to study abroad. African Journal of Business Management, 3(8), 358-365. https://doi.org/10.5897/AJBM09.117

Nababan, P. W. J. (1991). Language in education: The case of Indonesia. International Review of Education, 37(1), 115-131. https://doi.org/10.1007/BF00598171

Nguyen, T. C. (2011). Challenges of learning English in Australia towards students coming from selected Southeast Asian countries: Vietnam, Thailand and Indonesia. International Education Studies, 4(1), 13-20. https://doi.org/10.5539/ies.v4n1p13

Noels, K. A., Pon, G., \& Clement, R. (1996). Language, identity, and adjustment: The role of linguistic self-confidence in the acculturation process. Journal of Language and Social Psychology, 15(3), 246-264. https://doi.org/10.1177/0261927X960153003

Norris, E. M., \& Gillespie, J. (2009). How study abroad shapes global careers. Journal of Studies in International Education, 13(3), 382-397. https://doi.org/10.1177/1028315308319740

Novera, I. A. (2004). Indonesian postgraduate students studying in Australia: An examination of their academic, social and cultural experiences. International Education Journal, 5(4), 475-487.

Peirce, B. N. (1995). Social identity, investment, and language learning. TESOL Quarterly, 29(1), 9-31. https://doi.org/10.2307/3587803

Rendle-Short, J. (2009). The address term mate in Australian English: Is it still a masculine term? Australian Journal of Linguistics, 29(2), 245-268. https://doi.org/10.1080/07268600902823110

Samuelowicz, K. (1987). Learning problems of overseas students: Two sides of a story. Higher Education Research and Development, 6(2), 121-133. https://doi.org/10.1080/0729436870060204

Tsui, A. B., \& Tollefson, J. W. (2017). Language policy, culture, and identity in Asian contexts. Australia: Routledge. https://doi.org/10.4324/9781315092034

Vidal, C. P. (2014). Study abroad and formal instruction contrasted: The SALA project. In C. P. Vidal (Ed.), Language Acquisition in Study Abroad and Formal Instruction Contexts. (pp. 17-57). Amsterdam: John Benjamins Publishing Company. https://doi.org/10.1075/aals.13.03ch2

Woodward, K. (1997). Concepts of identity and difference. In K. Woodward (Eds.), Identity and Difference (pp. 
8-50). London, England: Sage.

Woolfolk, A., \& Margetts, K. (2016). Educational psychology. In M. Gindidis, S. Phillipson, M. Pruyn, \& P. Thanh (Eds.), Understanding Learning and Learners (pp. 31-185). Melbourne, VIC: Pearson Australia.

\section{Copyrights}

Copyright for this article is retained by the author(s), with first publication rights granted to the journal.

This is an open-access article distributed under the terms and conditions of the Creative Commons Attribution license (http://creativecommons.org/licenses/by/4.0/). 